\title{
From Psychiatric Interviews to Psychotherapies
}

\author{
Göka Erol', Çakmak Işık Batuhan and Erdoğan Ezgi Çisil
}

Department of Psychiatry, Ankara City Hospital, University of Health Sciences, Ankara, Turkey

*Corresponding author: Erol Göka, MD, Professor, Department of Psychiatry, Ankara City Hospital, Üniversiteler Mahallesi Bilkent Street, Nr: 1, TR06800, Çankaya/Ankara/Turkey, Tel: +903125526000

\begin{abstract}
Psychotherapy can be defined as a treatment method consisting of psychological tools whereby a trained expert works with a person or a group to resolve the patient's biopsychosocial problems through relation and communication.

There are numerous issues in psychotherapy practice that require further efforts to ground relevant concepts. Most psychiatrists' practices have shifted towards offering psychopharmacological treatment alone for a number of reasons, such as increasing patient volume, recent pharmacological developments, protocols on drug therapies, time restriction on doctors and so on. At the same time, it is important to know why people turn to psychiatry, what makes them benefit from psychiatric services, and why they have chosen psychiatry over other fields in medicine. The answers to these questions bring us to a place and value of psychotherapies in the curriculum of psychiatric training. In all kinds of psychiatric practices, the leading treatment factor is the doctor-patient relationship, which should be formed within the transference/countertransference framework.

What deems psychiatry different and more attractive than other fields of medicine are these skills, which can be collectively referred to as "psychotherapeutic intervention". The psychiatry resident should be equipped with several skills and knowledge on psychiatric interviews during their psychotherapy education in order to employ a successful psychotherapeutic intervention.

This paper aims to create a look into how psychotherapies and psychotherapeutic intervention should be understood and placed within current practices.
\end{abstract}

\section{Introduction}

Psychotherapy can be defined as a treatment method consisting of psychological tools whereby a trained expert works with a person or a group to alleviate emotional distress, form permanent changes in emotion and thought, and improve personality traits accordingly
$[1,2]$. This definition is in accordance with and a result of the "biopsychosocial (BPS) model," a comprehensive approach that has been founded on the principle of giving equal importance to biological, psychological, and social factors in all matters relating to health $[3,4]$. The BPS model considers the patient's personal and family history, physical and subjective experiences, and societal characteristics in diagnosis and treatment [3,57]. In this sense, psychotherapy can be defined as an effort to resolve the patient's biopsychosocial problems through relation and communication [3,7]. Even though it has been easy to agree on a definition, the panorama of the psychotherapeutic field reflects numerous issues in practice and requires further efforts to ground relevant concepts. By these concepts, we mean the contradictory situation between the rigid approach we see when we look at dimensions that do not match the definition of psychotherapy and its place in practice (such as fanatical psychotherapy schools, education and certification processes) rather than known problems in the field of psychotherapy $[1,8]$. As long as we cannot resolve this contradiction, no matter how flexible we define it, in the final analysis, psychotherapy turns into a viable treatment modality only after receiving training and certification from an institution that works only under a certain school, within the framework of the common understanding.

This paper aims to create a look into the use of psychotherapies within the current psychiatric and medical notions and seek to emphasize that a new concept such as "psychotherapeutic intervention" is needed to overcome the contradiction mentioned above or that this concept needs to be revived and its 
meaning expanded.

\section{Psychotherapy: A field of chaos}

Today, psychotherapies are divided into several schools based on their respective application methods as well as theories on development, identity and psychopathology [9]. This outlook complicates our ability to form an integrated approach and solid defense of psychotherapy. Field masters such as Wallace tend to view psychotherapy as "a craft that is more systematic, less personally innovative than art, and less rigorous and exact, more artistically creative than science" [10]. Other modern writers recommend methods classified according to areas where the patient faces difficulty and aims to change. Based on this principle, therapy and appropriate techniques should be selected in accordance with the emotional, cognitive, behavioral, interpersonal, and systematic causes underlying the patient's complaints [11]. Unfortunately, these attempts increase the level of existing confusion [12]. Furthermore, there are other obstacles to forming a shared understanding in the field of psychotherapy. These obstacles, which we will mention below, are also the reasons why a new perspective in psychotherapy is needed.

Even though psychotherapy is a field that initially arose under the umbrella of modern medicine, it has developed alongside with the psychological science of guidance and counseling services, and nonacademic practices such as "personal development," "life coaching," and "spiritual guidance." [13,14]. Therefore, the question of who a psychotherapist is, or more precisely who has the competency to practice psychotherapy, remains an important issue throughout the world [8]. The "progression" approach arising in every scientific area is usually not discussed for psychotherapy despite the existence of numerous new approaches and initiatives. For years, happenings in the psychotherapy field have been named "developments," "renewals," "waves," and even "trends" rather than "scientific progress." [15-17]. Although there has been numerous research on adapting psychotherapies into current scientific methods [18-20], there is no consensus on whether these approaches belong under a common roof or employ the same scientific and logical method $[2,13]$.

Similarly, the difficulty of scientific research into the comparative effectiveness of psychotherapies has remained over the years $[21,22]$. It is remarkable that in interviews with patients who received psychotherapy services, many mention the "interviewer's qualities" as the major beneficial factor $[12,23,24]$. This is emphasized further by Carl Rogers's approach, in which he founded client-centered psychotherapy and radically changed the outlook on psychotherapies [25]. Rogers defined the core aspects of a successful therapy as congruence, unconditional positive regard and empathy [26]. He claimed that it was sufficiently beneficial for the patient to listen to them effectively and compatibly, in an impartial, unloaded, non-judgmental manner, showing unconditional positive respect [25]. If these approaches highlighting psychotherapies' common points and the importance of the therapeutic relationship had been developed, a comprehensive psychotherapy view would have been served [15]. Instead, due to the chaos in this field, the effect was similar to a light flickering and then waning. However, in our opinion, the approaches that have been on the agenda since Rogers, pointing to the common points of psychotherapies and the importance of the therapeutic relationship (although they have been put forward for very different reasons apart from our claim) are of key importance in the resolution of the contradictory situation we have mentioned. In our opinion, if psychotherapies can have common points and an inclusive psychotherapy perspective can be developed from this point of view, an opportunity can be found for a solution. We will return to this point in the future, but first we want to focus on the place of psychotherapy in current psychiatric practices.

\section{Current Psychiatric Practices and Psychotherapies}

While the current specialization training in psychiatry includes psychotherapy in a mostly theoretical and partly practical fashion, a psychopharmacologycentered approach in patient-doctor relationships also occurs in practice [27]. In the first interview, the doctor aims to obtain the information necessary to diagnose, and immediately proceeds to prescribe one or more medications without taking into consideration the patient's psychological and social problems. In the following appointments, once again the doctor focuses on the medication's effects and side effects, ignoring psychological and social problems even if they are broached [28,29]. It is widely accepted that psychotherapeutic intervention equipped with a biopsychosocial understanding is indispensable in regulating, sustaining, and ending pharmacological healing [30,31]. Yet, little is said about how this can be achieved. In the course of this process, patients are invited to attend control interviews depending on the duration of the prescribed medication's effects and side effects [32]. Throughout the world, consulting to and expectations from psychiatric services have been increasing [33-35]. Let alone generating development in psychotherapies, this increase may cause a decrease in the average duration and the frequency of follow-up visits in psychiatric clinics. Even though this negative outlook has been broadly noticed, observable efforts have not been made to ameliorate the situation [10-14].

\section{The Increasing Appeal of Psychiatry}

Supporters of biological psychiatry may tend to see the picture we have just described in favor of their own understanding and, in particular, as an 
indicator of success in psychopharmacology. It is true that improvements in psychopharmacology and somatic therapies have a great role in increasing the effectiveness and functionality of psychiatry in the medical field [36]. These are the main reasons for the success of treatment in disorders that are well defined and have valid treatment algorithms such as schizophrenia, mood disorders, and anxiety disorders [27]. If analyzed further, however, this point of view may be shown to be incorrect. There are and should be factors that bring people to psychiatry and satisfy them apart from disorders that have relatively wellestablished diagnoses and treatment algorithms $[1,27]$. Although almost all branches of medicine, especially neurology, physical medicine and rehabilitation, family medicine, and urology benefit from the developments in psychopharmacology [37-41]; expectations from these developments, and its applications to the practice remain mainly to be the field of psychiatry. Research shows that the applications made to psychiatry outpatient clinics also include illnesses, personality and relationship problems whose diagnosis and treatment algorithms are not well established $[42,43]$. In this case, the following question arises: Why is the appeal of psychiatry increasing, even though the duration of the meetings is shortened and the strict psychotherapy sessions suggested by schools are not practiced? Why do people increasingly resort to psychiatry for problems that are not even known whether psychopharmacological approaches are beneficial? If we can find an answer to these questions, we will be a little closer to our purpose in writing this article.

The success and increasing appeal of psychiatry cannot be explained only through the success of psychopharmacology. Despite present problems, the main qualification that makes psychiatry distinctive from other branches of medicine is about the place of psychotherapies in psychiatry residency programs and the reflection of psychotherapies on the practice of psychiatrists $[30,44]$. The approach and skills that a psychiatrist exhibits (or should exhibit) in interviews are the most important properties that distinguish psychiatry from other branches of medicine $[45,46]$. In our opinion, these properties are based on psychotherapy skills developed during psychiatry residency. It is necessary to focus on the exact and permanent psychotherapeutic skills gained from these trainings rather than the school differentiations in psychotherapies and to make inferences based on these facts in psychiatric practice while looking for the common characteristics of psychotherapies. If the characteristics that a psychiatrist has and should have can be determined well, we can develop a more seminal approach to psychotherapies, and apart from this, it will undoubtedly make a big positive contribution to psychiatry and even to medical education.

\section{Psychotherapeutic Intervention and Thera- peutic Relationship}

We think such reasoning makes it mandatory to add "psychotherapeutic intervention" to the agenda along with the known schools of psychotherapy. This covers a wide range of applications from the interaction skills used by the therapist in the therapist-patient relationship to specific psychotherapy practices. To our knowledge, the common ground in all psychotherapies is the set of skills that can be described mainly as psychotherapeutic interventions $[47,48]$. Therefore, the perspective of finding "common ground for psychotherapies," needs to be explored and developed further.

It is known that the most contributing factor to emotional healing is "alliance" in all types of psychotherapies [48-51]. It is important in many respects to maintain the relationship within the frame planned by the physician with the advantage of theoretical knowledge [52]. This relationship consists of words, attitudes and behaviors of the physician, the design of the interview, the format of questions, and how responses are effectively observed and appropriate responses are given [53].

Components such as "hope", "trust", "freedom of expression/reaction", "faith", "love and embracement" are the glue holding therapeutic alliances together and help in developing a therapeutic relationship [54]. These components need to be examined individually to determine their unique contribution to therapeutic alliance $[53,55,56]$. Here, trust is defined as a feeling of confidence towards the physician's knowledge and skills and those skills and knowledge should be used in the right way. Hope provides the patient with a source of strength to combat the illness [57]. It is important, though, to build hope on a solid foundation. In contemporary practice, physicians might find themselves pushed to the point of being the unquestioned authority and may attempt to instill hope in a patient beyond acceptable limits, and they may inevitably do more harm than good. At this point, the objective should not be to cure the illness but to aid the patients to gain their hope back $[55,58]$.

It seems that the distinction between psychiatric interview and other interviews is the quality of the therapeutic interview, client's readiness for change, different expectations of the client and therapist, therapy strategies and techniques $[25,56,59]$. According to meta-analyses compiling the common points regarding the effectiveness of psychotherapies; it is estimated that $30-50 \%$ of the overall improvement could be attributed to the quality of the therapeutic alliance, $66 \%$ to client's expectation, and $12-15 \%$ to the differences between the types of therapies [60], [61]. Another review shows that goal consensus accounts for $20 \%$, empathy $9 \%$, therapeutic alliance $8 \%$, positive regard/affirmation $7 \%$, therapist genuineness $6 \%$, therapist-specific factors $5 \%$ of variances in therapy outcomes [62]. Therefore 
establishing and maintaining the therapeutic alliance in psychiatric interviews should be our priority.

The attachment of the client to the therapist within the therapeutic boundaries also impacts the quality of therapeutic alliance $[60,63]$. In medicine, with the exception of psychiatry, the time taken to treat "organic" diseases limits the attachment to the physician [64]. Also the patient's and physician's expectations being limited to fixing the acute pathology may stand in the way of therapeutic alliance.

Physician-patient relationships that are essential in all medical specialties, but only those to which psychiatry attached great importance to can be regarded as a part of "psychotherapeutic intervention." Indeed, psychiatry residency training highlights the importance of physician-patient relationship in terms of psychiatry when compared to other medical disciplines. If we can understand what makes psychiatry, psychiatric interview, and therapists different from other fields of medicine, then our perspective on psychotherapeutic intervention and common aspects of psychotherapies will become clearer. Below, we are going to discuss the major concepts of this psychotherapeutic intervention.

\section{Key Concepts of Psychiatric Interview}

\section{Informing, identifying the problem, clarifying and learning}

One aspect that makes psychiatry, psychiatric interview and interviewer different from other fields and specialists is the special attention given to learning processes and the effort to understand the patient [65]. During the psychiatry residency training, it is learned that a qualified physician-patient (or therapist-patient) relationship can only be established by informing the patient about the problem and the interview itself and further explaining in a way that the patient can identify and understand the problem $[48,66]$. Since, only the patient who understands and feels understood can move forward in recovery.

An interviewer who has been trained in psychotherapy and gained psychotherapeutic intervention skills can help the patient by attempting to identify the present issues and link themes of events. A physician (therapist) who understands, explains what he knows and sees and answers the questions with an effort to develop appropriate solutions to problems, helps the patient to calm his fear and anxiety. As the fear and anxiety subside, efforts to learn more and seek solutions increase. Thereafter, what is learned is reinforced by being repeated frequently during the interviews [67].

\section{Effective listening}

What makes psychiatric interview different from the history and clinical examination of other medical specialties is its focus on equipping the practitioner with the skills to listen and understand the patient
[68]. A good listener, who can listen effectively, relaxes the patient, shows that they want to listen, removes distractions, tries to be empathetic, gives enough time to the patient, controls their anger and also tries not to be judgemental [54]. In order to achieve active listening, it is recommended to avoid guessing what the patient is going to say next, ask for clarification to confirm understanding and pay attention not only to what is being said but also to the body language [69].

\section{Empathetic approval}

Besides effective listening, the most important element that ensures understanding and alliance is empathetic approval. Training to gain empathetic skills is, therefore, an inseparable part of the theoretical and practical psychiatric curriculum [70]. Feeling understood by the physician is an important form of psychological support for the patient. The physician should confirm that they understand the patient with their attitude and behaviour [48].

Empathy is described as the process of a person placing himself in others' position, looking at the events from their perspective, understanding their feelings and thoughts and conveying their stand $[68,71]$. People who listen with an empathetic understanding also manage to look from the outside without losing objectivity. They avoid criticizing and judging to the best of their ability. They seek to understand without praising, judging, criticizing or blaming the other.

While establishing empathy, it is important not to lose objectivity and become drowned in others' emotional intensity. What we say and how we say it are very much related to the intensity of these expressed emotions. This is why it is necessary to pay attention not only to the verbal reactions but also to posture, gestures, facial expressions, tone of voice and speech tempo $[29,48,69,72]$.

\section{Self-worth and the expression of emotions}

Another skill the psychiatric interviewers learn during their residency is trying to notice the mental needs of the patient and then attempting to treat them [73]. During psychiatry residency training, the basic need of a patient is underlined as getting unconditional positive respect and being valued. Therefore, meeting these needs in practice is considered important [54,74] and an interviewer who has completed a psychiatric training program is expected to know the importance of attitudes and behaviors that feed self-worth and increase self-confidence.

Another mental need for patients is the ability to voice emotions such as fear, anxiety, guilt, anger, rage, hopelessness, pessimism, and disappointment. The psychiatric interviewer trained in psychotherapy knowingly employs a flexible attitude during the interview to facilitate the voicing of these emotions. 
The patient feels that they can articulate all emotions without concern for blame or condemnation. The practitioner encourages the patient to elaborate further on issues raised previously [75].

\section{Conclusion}

What makes a psychiatrist stand out from the other specialists in other medical fields is the "psychotherapeutic intervention" skills. The basis and source of these "psychotherapeutic intervention" skills that the psychiatrist is equipped with is the theoretical and applied general psychotherapy knowledge. As stated before, "psychotherapeutic intervention" skills almost completely correspond to "common characteristics of psychotherapies" $[48,76]$. If we can reach a consensus on all these matters and pay attention to what skills psychiatry residency adds to the physician's repertoire, different skills psychiatrists possess and the aspects of psychiatric interview that differ from other medical examinations, we can have substantive understanding and possible solutions regarding the problems in today's medicine.

There are numerous reasons why psychiatric treatment practices increasingly center around discussions of drug effects and neglect psychotherapeutic and psychosocial interventions. These include the increasing patient volumes, recent developments in psychopharmacology, protocols on drug therapies for mental disorders, as well as the inability of DSM- 5 and ICD-10 in taking etiology, ego strength, family, social network and intrapsychic conflict into account in a comprehensive manner [77,78]. On the other hand, due to time restrictions on interviews in outpatient settings, employing specifically structured psychotherapy methods in therapy is not possible in practice $[29,77]$.

At the same time, discussions of why people turn to psychiatry, what makes them content in psychiatric services, and why they have chosen psychiatry over other fields in medicine is crucial [79]. This brings us to the place and the value of psychotherapies in the curriculum of psychiatry training. A psychiatry resident is equipped with several skills and knowledge of psychiatric sessions during their psychotherapy education. The major contributing factor to the healing process in psychotherapies is "alliance" $[49,80]$. Psychiatrists learn this throughout their entire education and try to apply their skills for the benefit of the patient based on an appropriate and reliable physician-patient relationship. What deems psychiatry different and more attractive than other fields of medicine are these skills, which can be collectively referred to as "psychotherapeutic intervention." Once we understand this, we can shape further analyses and discussions of "common characteristics of psychotherapies" in a more functional way [54]. As a result, we can equip psychiatry residents with lasting psychotherapeutic knowledge and skills, instead of throwing them into the chaotic and tense field of psychotherapy.

\section{Conflicts of Interests}

We, the authors of this manuscript, declare that we have no conflicts of interest.

\section{Role of the Funding Source}

This article did not receive any specific grant from funding agencies in the public, commercial, or not-forprofit sectors.

\section{References}

1. Gabbard GO (2009) A P Publishing, Textbook of Psychotherapeutic Treatments. American Psychiatric Pub.

2. Weissman M, Cuijpers $P$ (2017) Psychotherapy over the Last Four Decades. Harv Rev Psychiatry 25: 155-158.

3. Kusnanto H, Agustian D, Hilmanto D (2018) Biopsychosocial model of illnesses in primary care: A hermeneutic literature review. J Fam Med Prim care 7: 497-500.

4. Gilbert P (2019) Psychotherapy for the 21st century: An integrative, evolutionary, contextual, biopsychosocial approach. Psychol Psychother 92: 164-189.

5. Wolberg LR (1977) The Technique of Psychotherapy böl. Grune \& Stratton.

6. Grinker RRS (1964) A Struggle for Eclecticism Am J Psychiatry 121: 451-457.

7. Farre A, Rapley T (2017) The New Old (and Old New) Medical Model: Four Decades Navigating the Biomedical and Psychosocial Understandings of Health and IIIness. Healthc (Basel, Switzerland) 5: 4.

8. Kernberg OF (2016) Psychoanalytic Education at the Crossroads: Reformation, Change and the Future of Psychoanalytic Training. Routledge, Taylor \& Francis Group.

9. Corey G (2009) Theory and Practice of Counseling and Psychotherapy. Thomson Brooks/Cole.

10. Wallace ER (1983) Dynamic Psychiatry in Theory and Practice. Lea \&Febiger, 407.

11. Overholser JC (2020) 50 Years of Psychotherapy: Erudition, Evolution, and Evaluation. J Contemp Psychother 50: 87-93.

12. Sommers-Flanagan J, Sommers-Flanagan R (2015) Clinical Interviewing. Wiley.

13. Dupont S (2014) L'autodestruction du mouvement psychanalytique. Editions Gallimard.

14. Aboujaoude E (2020) Where Life Coaching Ends and Therapy Begins: Toward a Less Confusing Treatment Landscape. Perspect Psychol Sci A J Assoc Psychol Sci 15: 973-977.

15. Jones-Smith E (2021) Theories of counseling and psychotherapy: An integrative approach. ( $3^{\text {rd }}$ edn).

16. Hayes SC (2016) Acceptance and Commitment Therapy, Relational Frame Theory, and the Third Wave of Behavioral and Cognitive Therapies - Republished Article. Behav Ther 47: 869-885.

17. Thomason TC (2010) The trend toward evidence-based practice and the future of psychotherapy. Am J Psychother 64: 29-38.

18. McAleavey A, Youn SJ, Xiao H, Castonguay LG, Hayes JA, et al. (2019) Effectiveness of routine psychotherapy: Method matters. Psychother Res 29: 139-156. 
19. Dragioti E, Karathanos V, Gerdle B, Evangelou E (2017) Does psychotherapy work? An umbrella review of metaanalyses of randomized controlled trials. Acta Psychiatr Scand 136: 236-246.

20. Scott J (2017) The science and practice of psychotherapy: the critical need for quality assurance and vigilance to monitor the ratio of benefits to risks of therapies. Acta Psychiatrica Scandinavica 136: 233-235.

21. Shedler J (2018) Where Is the Evidence for 'EvidenceBased' Therapy? Psychiatr Clin North Am 41: 319-329.

22. Cook SC, Schwartz AC, Kaslow NJ (2017) EvidenceBased Psychotherapy: Advantages and Challenges. Neurotherapeutics 14: 537-545.

23. Carlat D (2016) The Psychiatric Interview. Wolters Kluwer Health.

24. Timulak L, Keogh D (2017) The client's perspective on (experiences of) psychotherapy: A practice friendly review. J Clin Psychol 73: 1556-1567.

25. Rogers CR (2007) Counseling and Psychotherapy. Read Books.

26. Rogers C (2012) On Becoming a Person: A Therapist's View of Psychotherapy. HMH Books.

27. Riba MB, Balon R, Roberts LW, Gabbard GO (2017) Competency in Combining Pharmacotherapy and Psychotherapy: Integrated and Split Treatment. American Psychiatric Publishing.

28. Huhn M, Tardy M, Spineli LM, Kissling W, Forstl H, et al. (2014) Efficacy of pharmacotherapy and psychotherapy for adult psychiatric disorders: A systematic overview of metaanalyses. JAMA Psychiatry 71: 706-715.

29. Özmen E, Taskin E (2007) Poliklinik Uygulamalarında Psikoterapötik Girişimler.

30. Rosenblum S, Frankel BL (1984) Teaching the biopsychosocial model to medical residents in an outpatient clinic. Psychosomatics 25: 751-759.

31. Silberman EK, Certa K, Kay A (2015) The Psychiatric Interview: Settings and Techniques. In: Psychiatry, John Wiley \& Sons, Ltd, 34-55.

32. Atbaşoğlu EC (2017) Biopsychosocial model and psychotheurapeutic approach in outpatient treatment settings Updat. Psychiatry J Psychiatr Assoc Turkey Contin Educ 7: 287-296.

33. Thomas KC, Ellis AR, Konrad TR, Holzer CE, Morrissey JP (2009) County-level estimates of mental health professional shortage in the United States. Psychiatr Serv 60: 13231328.

34. Thomas KC, Ellis AR, Konrad TR, Morrissey JP (2012) North Carolina's mental health workforce: unmet need, maldistribution, and no quickfixes. NC Med J 73: 161-168.

35. Robiner WN (2006) The mental health professions: workforce supply and demand, issues, and challenges. Clin Psychol Rev 26: 600-625.

36. Braslow JT, Marder SR (2019) History of Psychopharmacology. Annu Rev Clin Psychol 15: 25-50.

37. Kranzler JD, Gendreau JF, Rao SG (2002) The psychopharmacology of fibromyalgia: a drug development perspective. Psychopharmacol Bull 36: 165-213.

38. Benich JJ 3rd, Bragg SW, Freedy JR (2016) Psychopharmacology in Primary Care Settings. Prim Care 43: $327-340$.
39. Singh B, McArdle N, Hillman D (2019) Psychopharmacology of sleep disorders. Handb Clin Neurol 165: 345-364.

40. Ciaramella A (2019) Psychopharmacology of chronic pain. Handb Clin Neurol 165: 317-337.

41. Maguire M (2019) The psychopharmacology of epilepsy. Handb Clin Neurol 165: 207-227.

42. Tümkaya S, Özdel O, Değirmenci T, Kalkan Oğuzhanoğlu $N$ (2005) The diagnosis and treatment in psychiatric outpatients at university hospital: A retrospective study. Anatol J Psychiatry 6: 36-40.

43. Steel Z, Marnane C, Iranpour C, Chey T, Jackson JW, et al. (2014) The global prevalence of common mental disorders: a systematic review and meta-analysis 1980-2013. Int J Epidemiol 43: 476-493.

44. Emmelkamp PMG, David D, Beckers T, Muris P, Cuijpers $P$, et al. (2014) Advancing psychotherapy and evidencebased psychological interventions. Int J Methods Psychiatr Res 23: 58-91.

45. Corral I, Johnson TL, Shelton PG, Glass O (2017) Psychiatry Resident Training in Cultural Competence: An Educator's Toolkit. Psychiatr Q 88: 295-306.

46. Meresh ES, Daniels D, Rao M, Sharma A, Halaris A, et al. (2019) Experience Of Resident Presentations In Consultation-Liaison Psychiatry Grand Rounds: Increase Value For Clinical Education. Adv Med Educ Pract 10: 885890.

47. Frank D (1972) Common Features of Psychotherapy. Aust N Z J Psychiatry 6: 34-40.

48. Peterson BS (2019) Editorial: Common factors in the art of healing. Journal of Child Psychology and Psychiatry, and Allied Disciplines 60: 927-929.

49. Flückiger $C$, Del Re AC, Wampold BE, Symonds D, Horvath AO (2012) How central is the alliance in psychotherapy? A multilevel longitudinal meta-analysis. J Couns Psychol 59: 10-17.

50. Stubbe DE (2018) The Therapeutic Alliance: The Fundamental Element of Psychotherapy. Focus (Madison) 16: 402-403.

51. Ardito RB, Rabellino D (2011) Therapeutic alliance and outcome of psychotherapy: Historical excursus, measurements, and prospects for research. Front Psychol 2: 270.

52. Di Nuovo S (2019) What research for what training in psychotherapy? Some methodological issues and a proposal. Res Psychother 22: 410.

53. Lambert MJ, Ogles BM (2014) Common factors: post hoc explanation or empirically based therapy approach? Psychotherapy (Chic) 51: 500-504.

54. Cuijpers P, Reijnders M, Huibers MJH (2019) The Role of Common Factors in Psychotherapy Outcomes. Annu Rev Clin Psychol 15: 207-231.

55. Michael (2013) The efficacy and effectiveness of psychotherapy. Bergin Garfield's Handb Psychother Behav Chang 169-218.

56. Norcross JC, Lambert MJ (2019) Psychotherapy Relationships That Work: Volume 1. OXFORD University Press.

57. Vande Kemp H (1984) Hope in Psychotherapy. J Psychol Christ 3: 27-35.

58. Larsen D, Edey W, Lemay L (2007) Understanding the role 
of hope in counselling: Exploring the intentional uses of hope. Couns Psychol Q 20: 401-416.

59. Beitman BM, Yue D (2004) Learning Psychotherapy: A Time-Efficient, Research-Based, and Outcome-Measured Psychotherapy Training Program. ( $2^{\text {nd }}$ edn), WW Norton \& Company.

60. Arciniegas DB, Anderson CA, Filley CM (2013) Behaviora Neurology \& Neuropsychiatry. Cambridge University Press.

61. Wampold BE (2001) The Great Psychotherapy Debate: Models, Methods, and Findings. L Erlbaum Associates.

62. Laska M, Gurman AS, Wampold BE (2014) Expanding the lens of evidence-based practice in psychotherapy: A common factors perspective. Psychotherapy (Chic) 51: 467-481.

63. Levy K, Johnson B (2018) Attachment and Psychotherapy: Implications From Empirical Research. Can Psychol 60: 178-193.

64. Dugdale DC, Epstein R, Pantilat SZ (1999) Time and the patient-physician relationship. J Gen Intern Med 14: S34-S40.

65. Grassi L, Caruso R, Costantini A (2015) Communication with patients suffering from serious physical illness. Adv Psychosom Med 34: 10-23.

66. McCabe R, Healey PGT (2018) Miscommunication in Doctor-Patient Communication. Top Cogn Sci 10: 409-424.

67. Sotres-Bayon F, Bush DEA, LeDoux JE (2004) Emotional perseveration: An update on prefrontal-amygdala interactions in fear extinction. Learn Mem 11: 525-535.

68. Jackson SW (1992) The listening healer in the history of psychological healing. Am J Psychiatry 149: 1623-1632.

69. Göka E, Beyazyüz M (2019) Geçimsizler: KişilikleriTanımaveGeçinmeyiKolaylaştırmaKitabı. $\quad\left(2^{\text {nd }}\right.$ edn), KapıYayınları.
70. Riess H, Kelley JM, Bailey RW, Dunn EJ, Phillips M (2012) Empathy training for resident physicians: A randomized controlled trial of a neuroscience-informed curriculum. J Gen Intern Med 27: 1280-1286.

71. Decety J (2020) Empathy in Medicine: What It Is, and How Much We Really Need It. Am J Med 133: 561-566.

72. Lorié Á, Reinero DA, Phillips M, Zhang L, Riess H (2017) Culture and nonverbal expressions of empathy in clinical settings: A systematic review. Patient Educ Couns 100: 411-424.

73. Feinstein R, Heiman N, Yager J (2015) Common factors affecting psychotherapy outcomes: some implications for teaching psychotherapy. J Psychiatr Pract 21: 180-189.

74. Summers RF (2018) Teaching Psychotherapy to Psychiatry Residents. Psychodyn Psychiatry 46: 411-435.

75. Göka E (2019) İnsanKısımKısım. (3 $3^{\text {rd }}$ edn), İstanbul: VadiYayıncılık.

76. Wampold BE (2015) How important are the common factors in psychotherapy? An update. World Psychiatry 14: 270-277.

77. Gökalp P (2017) How can psychoanalytic orientation effect outpatient services? Are we talking about psychoanalysis in 15 minutes? Updat Psychiatry J Psychiatr Assoc Turkey Contin Educ 7: 297-306.

78. Vanheule S (2014) Diagnosis and the DSM: A Critical Review. Palgrave Macmillan UK.

79. Sparks JA, Duncan BL, Miller SD (2008) Common factors in psychotherapy. In: Twenty-first century psychotherapies: Contemporary approaches to theory and practice. John Wiley \& Sons Inc, Hoboken, NJ, US, 453-497.

80. Horvath AO, Del Re AC, Flückiger C, Symonds D (2011) Alliance in individual psychotherapy. Psychotherapy (Chic) 48: 9-16. 